\title{
FRENTE A LA ENCRUCIJADA DE LAS ETIQUETAS POLÍTICAS. EDITORIAL COSTA RICA, ESTADO E INTELECTUALES (1959-1987)
}

Diana Rojas Mejías*

\begin{abstract}
Resumen: Este artículo estudia la Editorial Costa Rica y sus publicaciones como espacios de disputa dentro del mundo intelectual, desde su creación en 1959 hasta su crisis económica en 1987. Para ello, profundiza en la fundación institucional, las discusiones políticas por el contenido de sus publicaciones y las amenazas de otras entidades por la comercialización de las obras.
\end{abstract}

Palabras clave: Editorial Costa Rica, publicaciones, literatura, política, editorial, intelectuales.

\begin{abstract}
This article studies the Editorial Costa Rica and its publications as space of disputes between intellectuals, since its creation at 1959 until its economic crisis at 1987. For that purpose, analyses the foundational process, the politics discusses about the topics of its publications and the treats of others entities to market literary works.
\end{abstract}

Keywords: Editorial Costa Rica, publications, literature, politic, publishers, intellectuals.

\section{Introducción}

$\square$ ste artículo estudia la Editorial Costa Rica -en adelante, ECR o Editorial- como un espacio de poder cultural. Proponemos que la Editorial y sus publicaciones se convirtieron en sitios de lucha entre intelectuales. Conceptualizamos su papel de esta manera porque la institución se creó sobre los cimientos del Estado Benefactor, el cual al ofrecer condiciones favorables de subvención la perfiló como el principal ente de promoción de la literatura. Por momentos, esta situación desencadenó disputas por el acceso a sus puestos y a

Fecha de recepción: 13/10/2015 - Fecha de aceptación: 19/02/2016

* Costarricense. Bachiller en Historia por la Universidad Nacional de Costa Rica (UNA). Egresada de la Maestría en Historia Aplicada de la Universidad Nacional. Correo electrónico: dianarome2389@gmail.com 
sus programas de publicaciones. Y por otros, las divisiones políticas heredadas del conflicto de 1948 y el contexto global de polarización ideológica, canalizaron los debates hacia la función política de la Editorial y el alcance de sus publicaciones en el público lector.

A partir de entonces, sostenemos, los motores de lucha entre intelectuales tuvieron tres dimensiones. La primera giró en torno a la asignación de recursos estatales y a la oportunidad, con ello, de cubrir el costo total del libro. La segunda se vinculó con la legitimidad literaria otorgada por la institución y las posibilidades de dar a conocer las creaciones artísticas a través de un canal oficial del Estado. Finalmente, la tercera se relacionó con la afinidad ideológica de los autores y autoras, y las consecuencias para la Editorial de publicar sus obras.

El trabajo inicia con el análisis de la creación de la Editorial en 1959 y concluye con su crisis económica en 1987. Un período que se vincula, respectivamente, con la implementación y el agotamiento de las políticas culturales del proyecto socialdemócrata. A través de fuentes como el proyecto de ley, las actas institucionales y los artículos de prensa, estudiamos desde la Editorial las limitaciones de este modelo de Estado y las principales discusiones ideológicas de las décadas filtradas en la aprobación -o no- de sus publicaciones.

El análisis del tema se aborda en cuatro apartados. En el primero de ellos, se realiza un balance de las principales investigaciones relacionadas con nuestro objeto de estudio. Desde estos enfoques, la Editorial solo se consideró como una institución administrativa y emblemática. Fueron los estudios en historia y literatura los que visibilizaron, brevemente, el proyecto político de la Editorial. Por ello, en el segundo apartado, se contextualiza su proceso de creación y su representatividad en el medio nacional. En la tercera sección, se explica la manera en que los debates políticos de la esfera pública se trasladaron al Consejo Directivo. Estas discusiones se analizan a través de la publicación de tres casos: las obras de Carlos Luis Fallas y los escritores de izquierda, las tesis políticas de Carlos Araya Pochet y Óscar Aguilar Bulgarelli, y los tomos sobre el pensamiento político costarricense. Finalmente, en el cuarto apartado se estudia el surgimiento de una serie de dependencias del Estado y nuevas editoriales que amenazaron el mercado nacional de publicaciones y presionaron la capacidad de respuesta de la Editorial para la comercialización de obras.

\section{La Editorial Costa Rica como objeto de estudio}

Los estudios de la Editorial Costa Rica surgieron en la década de 1990. Esta tendencia se pudo explicar por la crisis económica de la institución sufrida en los años $1986-1987^{1}$ y el interés de las investigaciones por analizar sus

1 Archivo Nacional de Costa Rica -en adelante, ANCR-. Fondo: Editorial Costa Rica. Acta 22, 6 de enero - 15 de diciembre de 1986; Acta 23, 5 de enero - 27 de julio de 1987; Acta 24, 3 de agosto - 21 de diciembre de 1987. 
razones. En el marco de este contexto, los estudios visibilizaron la relevancia del tema. Desde distintos enfoques, coincidieron en que la importancia de este objeto de estudio fue el carácter estatal de la Editorial y los beneficios que esta condición otorgó a la literatura al cubrir el costo total de la producción del libro.

Así, por ejemplo, los estudios de Manuel Hernández y Guillermo Zamora se enfocaron en el funcionamiento financiero de la Editorial en los noventas. ${ }^{2}$ Con base en un enfoque administrativo, encontraron las causas de la crisis en las inconsistentes políticas de planificación y mercadeo, la dependencia a la subvención del Estado, el aumento en la planilla y las deudas. A pesar de sus hallazgos, los trabajos solo ofrecieron una evaluación organizacional a corto plazo y se concentraron en una lista de recomendaciones para repensar las posibilidades de sobrevivencia empresarial en la industria editorial.

La Editorial volvió a capturar la atención desde un enfoque conmemorativo. A las explicaciones administrativas se les sumó una nueva perspectiva focalizada en la institución como un aporte a la educación y la "cultura nacional". Desde este planteamiento, la Editorial se exaltó por su promoción artística, su rescate a la literatura, sus actos de entrega de libros, sus certámenes y colecciones especiales. ${ }^{3}$ Sin embargo, estos trabajos solo contribuyeron con descripciones breves, por lo general, con intenciones de reivindicar a sus personajes fundadores, sus aniversarios y su prestancia en el medio cultural.

En este recorrido por las principales investigaciones, fueron los trabajos producidos en historia y literatura los que aportaron un enfoque crítico. De esta manera, para Arturo Arias en el contexto centroamericano de 1945-1970, se perfiló como "la primera editorial nacional centroamericana" y uno de los ejemplos por institucionalizar la cultura. ${ }^{4}$ Desde la perspectiva de Rafael Cuevas, representó la necesidad de atender la demanda del sector intelectual y cooptar a los

2 Manuel Hernández, Editorial Costa Rica: Diagnóstico de la organización administrativa de la Editorial Costa Rica (San José, Costa Rica: Centro de Investigación y Capacitación en Administración Pública CICAP, 1990); Guillermo Zamora, Reto de la Editorial Costa Rica ante los conceptos de globalización y reforma del Estado costarricense (Tesis de Maestría en Administración de Negocios, Universidad de Costa Rica, 1999). El trabajo de Hernández es un estudio solicitado por Habib Succar, entonces gerente de la ECR al CICAP, para evaluar las áreas administrativas, financieras, de recursos humanos, producción, mercadeo y recursos materiales. El trabajo de Zamora se concentra en la situación financiera del período de 1993-1997 con base en la información del Departamento Financiero de la ECR, la Contraloría General de la República y el Ministerio de Hacienda.

3 Estrella Cartín de Guier, "La Editorial Costa Rica. Las entregas de libros en la Editorial Costa Rica", Káñina (Costa Rica) 9, n.1 (1985): 215; Osvaldo Valerín, Editorial Costa Rica, 40 aniversario (San José, Costa Rica: Fundación Cívica y su Historia, 2000) Audiovisual; Editorial Costa Rica, Memoria Conmemorativa 50 aniversario (San José, Costa Rica: ECR, 2009); Álvaro Quesada, Breve historia de la literatura costarricense (San José, Costa Rica: ECR, 2008), 101; Eloy Morúa, Programa de educación. Ley de la Editorial Costa Rica y los Premios Nacionales (San José, Costa Rica: Programa de Gobierno No. 4, s. f.).

4 Arturo Arias, Gestos ceremoniales. Narrativa centroamericana (1960-1990) (Guatemala: Artemis-Edinter, 1998), 32-33. Arias menciona que hubo un intento preliminar pero fallido en Guatemala. 
intelectuales de izquierda al proyecto socialdemócrata. ${ }^{5}$ Según Magda Zavala, en el marco de la posguerra centroamericana y la globalización, contribuyó con la creación del canon literario y controló la selección de obras a través de cúpulas de escritores posicionados en la institución. ${ }^{6} \mathrm{Y}$ para Carlos Cortés, como parte del proyecto cultural socialdemócrata consagró una literatura nacionalista siguiendo los valores liberales del siglo XIX -realismo, nacionalismo y paternalismo-. ${ }^{7}$ A pesar de estos sugerentes puntos de vista, no profundizaron en sus ideas ni ofrecieron una reflexión a largo plazo, con pruebas o ejemplos, para sostener sus señalamientos.

En el balance anterior sistematizamos los estudios más próximos al objeto de estudio. En esencia, brindaron recomendaciones administrativas para superar la crisis; descripciones conmemorativas para destacar los logros y cuestionamientos exploratorios para evidenciar intencionalidades políticas. Nuestra propuesta, en cambio, entiende la Editorial y sus publicaciones como espacios de pugna entre intelectuales. Sostenemos que, en distintos momentos de su historia, la institución y sus productos se convirtieron en sedes de lucha ideológica y disputas por la obtención de sus recursos. Partimos de su proyecto fundacional para comprender la representatividad de la institución en el medio nacional. Luego, nos trasladamos a los debates generados por el contenido de las obras, discusiones comprendidas a luz de las divisiones políticas del conflicto del 48 . Y concluimos estas pugnas, con la amenaza gestada por otras entidades para absorber sus beneficios estatales y competir en el mercado nacional de publicaciones.

\section{“Gobernar es educar": Proyecto político y fundacional de la Editorial del Estado}

La creación de la ECR involucró dos fechas claves y un personaje central. ${ }^{8}$ Según el intelectual socialdemócrata Alberto Cañas, en 1955 se llevó a cabo una

5 Rafael Cuevas, El punto sobre la i. Políticas culturales en Costa Rica (1948-1990) (San José, Costa Rica: Ministerio de Cultura, Juventud y Deportes - MCJD, 1996), 96-98.

6 Magda Zavala, "Globalización y literatura en América Central: Escritores y editoriales", en: Interacciones y transgresiones: Propuestas para una historiografia literaria en Centroamérica. Tomo I, (ed.) Werner Mackenbach (Guatemala: F\&G Editores, 2008). Aunque Zavala aclara que la publicación en una editorial estatal tampoco garantiza reconocimiento, debido a la diversidad de temas publicados y a las limitaciones de distribución. Es importante aclarar, además, que en la construcción -o deconstrucción- del canon entran varios agentes: prensa, academia, premios, sistema educativo, mercado, entre otros; por lo que no bastaría con la participación de una editorial para controlarlo. O bien, otra manera de entenderlo sería la presencia de varios canones aprobados por estas instancias que coexisten al mismo tiempo o que se reemplazan entre sí cada cierto tiempo.

7 Carlos Cortés, La gran novela perdida. Historia personal de la narrativa costarrisible (San José, Costa Rica: Editorial Uruk, 2010). El escritor señala que la literatura nacional se promovió con las colecciones de la Biblioteca de Autores Costarricenses, Clásicos Costarricenses y Biblioteca Patria.

8 En esta sección se puntualizan como fechas claves 1955 y 1959. Sin embargo, en la prensa aparecen breves menciones a la necesidad de un editorial desde algunos años anteriores, por ejemplo consultar: s.a., "La dirección de la Biblioteca propone la creación de una editorial nacional", Diario de Costa Rica, 17 de junio 
reunión de escritores y editores en el Ministerio de Relaciones Exteriores. En esta oportunidad, Fernando Volio expuso una serie de solicitudes enviadas por diplomáticos residentes fuera del país. Entre sus demandas, expresaron la necesidad de contar con información impresa sobre Costa Rica para divulgar en el exterior. $^{9}$ A raíz de esta situación, la reunión de intelectuales derivó en una comisión encargada de formular el proyecto editorial. ${ }^{10}$ Una vez concluida la redacción de los lineamientos generales de operación, Volio en calidad de diputado trasladó la propuesta a la Asamblea Legislativa, aprobada finalmente en 1958 y publicada como Ley No. 2.366 el 10 de junio de 1959.

Así planteado, el proyecto de ley fue bien recibido en el plenario. El principal inconveniente, recuerda Cañas, fue el seguimiento político del anteproyecto en la Asamblea desde su formulación en 1955-1956 hasta su ratificación oficial en 1958-1959. ${ }^{11}$ No obstante, en su proceso de creación confluyeron dos formas de comprender la existencia editorial y la producción artística. Por un lado, una versión sostuvo que "nosotros no podemos presumir de un buen poeta, de un buen pintor, ni de un buen músico, ni de un buen escultor". ${ }^{12}$ Según este punto de vista, Costa Rica destacaba por el ingenio en la actividad política y no en la creación artística. Motivo suficiente para respaldar ahora este renovado

de 1953, 12; s.a., "Recomiendan la Editorial Nacional", La Nación, 14 de agosto de 1954, 7; s.a., "Respaldo a la iniciativa para crear una Editorial Nacional", Diario de Costa Rica, 22 de agosto de 1954, 16. Cabe aclarar que Fernando Volio aparece como figura central en tanto realiza la convocatoria de reunión y respalda el proyecto de ley en la Asamblea Legislativa. Sin embargo, como se detalla en la comisión redactora un conjunto de personalidades contribuyen a la gestación de la idea. Además, el proyecto había circulado por el respaldo del diputado Carlos Manuel Vicente Castro en 1954. Finalmente, la aprobación se logró en la administración de Mario Echandi, en la cual Volio ejerció una diputación con el Partido Independiente Jorge Volio.

9 Entrevista personal con Alberto Cañas. Realizada el 23 de setiembre de 2013, San José, Costa Rica. Este hecho lo registra el autor Rafael Cuevas en su libro El punto sobre la i..., 90. Sin embargo, construye la información con base en la obra de Jorge Valdeperas, Para una nueva interpretación de la literatura costarricense (San José, Costa Rica: ECR, 1979) y artículos de prensa. Datos que lo conducen a sostener una versión diferente. Citando a Valdeperas, Cuevas señala que fue Volio el interesado en divulgar obras en las embajadas del país. No obstante, pronto se enfrentó con las limitaciones económicas de publicar libros, razones suficientes para argumentar la urgencia de una editorial estatal. Para mayor detalle del evento, consultar Lía Coronado, "Asociación de autores y compositores costarricenses”, Diario de Costa Rica, 15 de enero de 1961, 25.

10 La comisión redactora estuvo integrada por Virginia Grütter, Fabián Dobles, Carlos Salazar Herrera, Carlos Aguilar, Arnoldo Herrera, Eduardo Jenkins, Gilberto Murillo, Antonio Lehman, Antidio Cabal y Fernando Volio. El anteproyecto fue trasladado por el Consejo de Gobierno a Alberto Cañas y Uladislao Gámez para que entregaran una versión acabada. Asamblea Legislativa. Fernando Volio, Ley de la Editorial Costa Rica, decreto 2.366. Sección "Proyecto", 2.

11 En un principio el proyecto descartó la edición de libros de texto, por el riesgo de comprometer la situación financiera de la Editorial. No obstante, la publicación de las obras didácticas se incluyó en la reforma de Ley No. 2.478 del 2 de diciembre de 1959. Las objeciones en esta reforma se vincularon con la sostenibilidad económica del proyecto a largo plazo y los requisitos de autores y autoras miembros. Consultar: s.a., "Es muy complicada la ley de la Editorial Nacional", La Prensa Libre, 22 de junio de 1959, 2; Ismael Cortés, "Objeciones al proyecto de la Editora Nacional”, La República, 24 de mayo de 1959, 16.

12 Asamblea Legislativa. Fernando Volio, Ley de la Editorial Costa Rica, decreto 2.366. Sección "Dictamen", 15. Las firmas de este apartado correspondieron a Rosa Alpina, Enrique Obregón y Marta Saborío. 
movimiento en el campo de las letras. Por el contrario, otra perspectiva justificaba la urgencia de un canal para "hacer llegar a conocimiento del público la existencia, la realidad y la calidad" de las obras costarricenses. De esta manera, se revelarían las "facultades creadoras" de los escritores y escritoras nacionales, enorgulleciendo al país con "altos valores estéticos y espirituales". ${ }^{13}$

El hito fundacional de la Editorial en el fondo revistió antiguas mitificaciones de la historia costarricense. Para un lado, partió de una demanda internacional y de la posibilidad de proyectar la "cultura nacional" impresa al exterior. ${ }^{14}$ Desde esta línea, retomaba la concepción política, habitual a finales del siglo XIX,${ }^{15}$ de fundamentar las instituciones culturales con el argumento de exponer y difundir la imagen nacional. Condición identificada, incluso en una fecha tardía como 1985. Para entonces, el presidente Luis Alberto Monge, con la urgencia de anunciar la posición de Costa Rica frente al conflicto centroamericano, comunicó a la ECR la disponibilidad de financiamiento para la publicación expedita de

13 Ibid. Sección "Proyecto", 3. En esta versión también se recomienda consultar s.a., "Gestase apoyo a la Editorial Nacional", La Prensa Libre, 20 de mayo de 1959, 1 y 3. En esta ocasión, los intelectuales comentaron que la importancia del proyecto radicó en potenciar a Costa Rica en la zaga centroamericana -Rodrigo Facio-, revivir los autores del pasado y valorar la producción juvenil -Enrique Macaya-. La relevancia de la institución, "objeto de mejor cuidado de los gobernantes costarricenses”, también se justificó por su aporte "en la cultura, en la enseñanza, en la orientación cívica y espiritual que el país requiere", s.a., "Conveniencia de la Editorial Nacional", La Prensa Libre, 20 de mayo de 1959, 2.

14 Las primeras obras aprobadas fueron Arqueología criminal americana de Anastasio Alfaro -1960-, Al través de mi vida de Carlos Gagini -1961-, A lo largo del corto camino de Yolanda Oreamuno -1961-; Corazón de una historia de Ricardo Ulloa -1961-; Memorias de Mario Sancho -1961-; Biografia sobre Melico Salazar de Manuel Segura -1961- y Obras completas de Mario Jiménez -1961-. De momento desconocemos las razones de esta escogencia; sin embargo, en la entrevista cita Cañas señaló que la guía para seleccionar autores se basó en las historias de la literatura de Rogelio Sotela y principalmente de Abelardo Bonilla. Siguiendo la catalogación de esta última referencia, podría pensarse que estos escritores y escritoras se eligieron por mostrar la producción costarricense en distintas áreas de la creación literaria: ensayo científico, novela, lírica, ensayo político-social, biografía e historia. Por otro lado, esta idea de publicar para enorgullecer al país se retomó en 1971, cuyo autor anónimo al reflexionar sobre el recorte presupuestario, recordó que "Don Faustino Sarmiento decía que gobernar es educar. Editar buenos libros, distribuirlos, hacer que las gentes los lean y llevar a todos los rincones del país y aun en el extranjero, a los autores nacionales, es una labor meritoria", s.a., "Editorial Costa Rica en la cultura del país", Diario de Costa Rica, 8 de octubre de 1971, 4. En 1973 se repitió esta percepción; ya que los libros de la Editorial "cumplen la importantísima labor de difundir y crear nuestra herencia cultural, divulgando por todo el país nuestra cultura, el ser y las ideas de nuestra historia y de nuestro pueblo, los valores auténticamente costarricenses... rompiendo nuestras fronteras y llevando nuestros valores culturales al plano internacional", s.a., "Una conquista del ser costarricense", La Nación, 11 de junio de 1973, 81. Y hacia 1982 se conceptualizó como un baluarte para fomentar la "consciencia nacional", Editorial Costa Rica, Boletín literario (Costa Rica) 5 (junio 1982): 1.

15 Ericka Gólcher, Consolidación del Estado Liberal: Imagen nacional y políticas culturales (1880-1914) (San José, Costa Rica: Publicaciones de la Cátedra de Historia de las Instituciones de Costa Rica, 1993). Al respecto se puede mencionar el caso de la creación del Archivo Nacional -1881-, Dirección General de Estadística -1883-, Museo Nacional -1887-, Biblioteca Nacional -1888-, Instituto Físico-Geográfico -1888- y Teatro Nacional -1890-. Para entonces, una imagen nacional asociada con la exhibición de un pasado histórico y culto; así como la demostración del conocimiento geográfico y poblacional del país. 
La neutralidad y la paz, obra que hacía constatar el "desarrollo de esta institución jurídica en la vida política de la nación". ${ }^{16}$

Por otro lado, el hito fundacional implicó el reconocimiento público y la revalorización de la producción literaria. Este acto condujo a romper con la percepción de la pobreza artística, la inexistencia de una "tradición", la "pequeñez de nuestro ambiente" y la "vida pueblerina"; según la crítica, limitantes del genio creador. ${ }^{17}$ No obstante estas reconceptualizaciones, la fundación de la ECR también reveló el comportamiento del público lector; puesto que la preocupación por abrir un espacio especializado para la edición, publicación y circulación de material literario se concretaría hasta $1960,{ }^{18}$ trasladando la interrogante de quiénes serían los sujetos productores de las obras a quiénes serían las personas consumidoras.

16 Acta 21, Sesión 1.146, 9 de setiembre de 1985, 155-156. La solicitud fue enviada a través de Armando Vargas, Ministro de Información y Comunicación y autor de la obra, quien escribió: “Con instrucciones del señor Presidente de la República, me dirijo a usted para comunicar a los señores directivos de la Editorial Costa Rica el interés que él tiene de ver publicadas, si fuese posible este mismo año, dos obras: Crónicas de la época y vida de don Ricardo por Joaquín Vargas Coto, y La neutralidad y la paz de Costa Rica que estoy preparando personalmente... En los dos casos, la Presidencia de la República cubrirá los costos de impresión y se asegurará que la Imprenta Nacional atienda con prioridad la producción”. La primera fue publicada por la ECR en 1986 y la segunda, posiblemente por la demora en la impresión, fue publicada por la Secretaría de Información y Comunicación en 1984 y 1985.

17 En el campo de la literatura estas ideas las encontramos, por ejemplo, en referencias como Abelardo Bonilla, Historia de la literatura costarricense (San José, Costa Rica: Stvdivm Generale Costarricense, 1984): 32-34; Alberto Cañas y Carlos Catania, "Entrevista sobre narrativa costarricense", Tertulia (Costa Rica) 4 (noviembre-diciembre 1972): 31-27.

18 Existen trabajos que ubican en fechas tan tempranas como 1830 las primeras imprentas de Costa Rica. Sin embargo, funcionaron como talleres de impresión, concentradas en la capital josefina, y dedicadas a la papelería estatal -y en alguna medida a revistas, periódicos, libros y folletos-. Iván Molina se refiere a un aumento de las capas lectoras a partir de 1880 con la producción de obras literarias, científicas y ensayos sociales; no obstantes restringidos a círculos intelectuales de anarquistas y socialistas. Iván Molina, "Al pie de la imprenta: La empresa Alsina y la cultura costarricense (1903-1914)", en: Avances de investigación, 69 (Centro de Investigaciones Históricas, Universidad de Costa Rica, 1994); Iván Molina, Una imprenta de provincia: El taller de los Sibajas en Alajuela, Costa Rica: 1867-1969 (Alajuela, Costa Rica: Museo Histórico Cultural Juan Santamaría, 2002); Ivonne Morales, La Imprenta Nacional dentro del aparato estatal (Tesis de Licenciatura en Derecho, Universidad de Costa Rica, 1990). Por otro lado, encuestas realizadas en la década de 1980 en San José, concluyeron que la lectura en la población muestreada se limitó al consumo de revistas y periódicos. Una lectura además relegada por la presencia de otras actividades, como el deporte, la televisión y los programas radiales. Los motivos de lectura fueron los requisitos del sistema educativo o la especialidad laboral. Ana Lucía Jiménez y Walter Solano, Hábitos de lectura y empleo del tiempo ocio en estudiantes y profesionales del cantón central de San José (Tesis de Licenciatura en Bibliotecología y Ciencias de la Información, Universidad de Costa Rica, 1985); Miguel González y Lidiette Diéz, Políticas editoriales, comercialización del libro y hábitos de lectura en el área metropolitana de San José en 1979 (San José, Costa Rica: Instituto Centroamericano de Estadística, 1980). Incluso en 2006 una investigación formuló una propuesta para lograr campañas de lectura efectivas, debido a la connotación negativa del concepto y de la práctica en nuestro país. Jacqueline Murillo, Todos saben qué es un libro, o ¿no?: Análisis arqueológico de los discursos del libro desde el pre(texto) de cinco informes de encuestas sobre "hábitos de lectura", Costa Rica (1979-2004) (Tesis de Maestría en Comunicación, Universidad de Costa Rica, 2006). La ECR reconoció como su principal agente de consumo al Ministerio de Educación Pública, el cual garantizaba ventas por los libros de texto y las lecturas obligatorias. Hasta la fecha no se han localizado estas listas de obras, solo referencias segmentadas, como por ejemplo ANCR, Fondo: Educación, Signatura: 5.096. Correspondencia de Carlos Alberto Arce -Administrador ECR- con Fernando Volio -Ministro de Educación-, 24 de mayo 1974. 
La relevancia de la Editoral y de su proyecto institucional se asoció a tres razones principales. En primer lugar, el capital económico fue suministrado por la subvención estatal, las deducciones del impuesto de renta, la ley de marcas y las utilidades de la venta de ediciones. Por tanto, la institución financió en su totalidad los derechos de autor, el costo y la publicidad de los libros. En segundo lugar, el Consejo Directivo conformó comités de lectura de tres personas para evaluar las obras. ${ }^{19}$ Esto significó la asignación de dietas por evaluación o edición; y de acuerdo con los informes, la aprobación inmediata del libro, sin pasar por otra instancia de intermediación. ${ }^{20}$ Finalmente, la ECR organizó sus escritos en las colecciones Colibrí, Nuestros clásicos, Clásicos de la literatura universal, Biblioteca Patria y otorgó premios como Carmen Lyra -1972-, Editorial Costa Rica -1972- y Joven Creación -1976-. ${ }^{21}$

El proyecto editorial formó parte de un conjunto de instituciones en la gestión del arte y la literatura. También era la época de los Premios Nacionales -1961-, la Dirección General de Artes y Letras -1963-, posteriormente Ministerio de Cultura, Juventud y Deportes (MCJD) -1971- y sus adscritos en cine, teatro, música, danza, entre otros. A pesar de este nacimiento dentro de la política cultural del Estado, la ECR encargada de "lo más selecto de las letras nacionales", ${ }^{22}$ tuvo que rendir cuentas de sus publicaciones. Como veremos a continuación, los debates políticos se filtraron en las decisiones intelectuales del Consejo y en la manera de valorar la labor de la entidad en la prensa.

\section{"La ingrata época de la "cacería de brujas". Publicar después del conflicto de 1948}

Desde su puesta en marcha en la década de 1960, la labor de la ECR se sometió al escrutinio público. Aparte de las inconformidades en el funcionamiento

19 La jerarquía organizacional en un inicio fue: Asamblea de Autores, Consejo Directivo, Comité de Selección, Administrador General y personal especializado. Estructura transformada en 1987 para incluir la gerencia, la auditoría interna, la asesoría legal y la producción editorial. Asamblea Legislativa. Fernando Volio, Ley de la Editorial Costa Rica, decreto 2.366. Sección "Decreto de ley", 66.

20 Los informes dictaminadores no se han localizado. La pérdida de esta información se puede explicar por dos razones. Para empezar, esta información confidencial solo fue del conocimiento de miembros del Consejo Directivo. Y al parecer no siempre se entregaron impresos, ya que hacia 1985 acordaron "fijar, como política editorial, que los lectores del Consejo Directivo emitan sus juicios por escrito". Acta 21, Sesión 1.151, 14 de octubre de 1985, 186. En ocasiones se mencionaron como motivos de desaprobación el grado de especialización del tema, o bien, graves problemas gramaticales y sintácticos.

21 Thais Aguilar, “A tono con la época”, La Nación, 27 de abril de 1987, 2B. La ECR en sus actas no explicó las características de estas colecciones ni quienes las formaban. El dato se obtiene de esta referencia de prensa. Agregamos que la institución tuvo dos canales de difusión: la revista Pórtico y el Boletín literario. Circularon por breves años el primero en la década de 1960 y el segundo en la década de 1980.

22 Consejo Directivo: Lilia Ramos -presidenta-, Alfonso Ulloa -secretario-, Julián Marchena, Arturo Echeverría, Enrique Macaya, Fernando Centeno, Carlos Meléndez. Presentación. En Pórtico (Costa Rica) 1, no. 1 (enero-abril): 183. 
administrativo señaladas por la Contraloría General de la República, ${ }^{23}$ la institución se enfrenó a la encrucijada de las etiquetas políticas. La necesidad de esclarecer el posicionamiento editorial devino en una constante fuerza tensora, fuera y dentro del Consejo Directivo. Para entonces, la preocupación se centró en la afinidad ideológica de quienes poseían cuotas de participación en la Editorial, y en la posible influencia ejercida para la selección y publicación de las obras.

Sin negar el contexto global de polarización, los siguientes tres casos reflejaron que las diferencias políticas del conflicto armado de 1948 traspasaron las décadas. El primer caso representa el discurso anticomunista, detectado desde la aparición del Partido en las campañas de 1930-1940, pero intensificado con los (des)acuerdos posteriores al enfrentamiento civil. En ese sentido, hacia las décadas de 1960-1970 la ECR tuvo que justificar ante la opinión pública la publicación de Carlos Luis Fallas y los escritores comunistas; así como las estrategias empleadas para impermeabilizar a la institución del avance comunista.

El segundo caso retoma la problemática de revisitar el conflicto desde la investigación histórica. Las tesis de Carlos Araya Pochet y Óscar Aguilar Bulgarelli sentaron sobre la mesa de discusión las consecuencias de publicar las memorias del 48. Este debate se centró en la búsqueda de "la verdad histórica" de los hechos y en los posibles efectos emocionales del recuerdo. Todo ello se llevó a cabo en un período próximo a la campaña electoral de 1970, la cual postularía a uno de principales protagonistas del 48, José Figueres, a la administración presidencial por tercera vez.

El tercer caso aborda el intento por conformar una colección sobre el pensamiento político costarricense. Las corrientes ideológicas se definieron únicamente desde dos tendencias: la socialdemocracia y el socialismo-marxista. Las apelaciones del editor, Joaquín Gutiérrez, revelaron el posible uso político de las publicaciones, ya fuera como medio de propaganda o de desprestigio. El segundo tomo, sobre todo, sucintó el desvelo del editor por las posibles interpretaciones del público de Manuel Mora, otro protagonista del 48, que para la década de 1980 entró en polémica por la separación de su partido.

En este escenario general entenderemos las discusiones del Consejo. En distintas décadas, los grupos directivos se cuestionaron ¿qué obras debían reconocer de un escritor?, ¿cuáles implicaciones traería consigo? y, ¿cómo esclarecer la "neutralidad" de la institución en medio de estos contextos? Fueron las creaciones de Carlos Luis Fallas y los escritores comunistas, las tesis sobre historia política de Carlos Araya Pochet y Óscar Aguilar Bulgarelli, así como los autores de la colección sobre el pensamiento político costarricense, quienes avivaron estas interrogantes.

23 Este tema escapa a nuestro interés. Al respecto se puede consultar: Acta 1, 3 de setiembre de 1965, 355; Acta 3, Sesión 301, 6 de diciembre de 1968, 18. 
El autor Manuel Gamboa sostiene que el discurso anticomunista se empleó como una herramienta para desacreditar al adversario político e infundir un temor irracional en la población. Gamboa argumenta que el recuerdo del 48 en la prensa responsabilizó a la izquierda de las consecuencias políticas y humanas, presentándola ante la opinión pública como una corriente fuera de los principios constitucionales. El comunista, aunque no se tuviera precisión del concepto, representó al "enemigo de la república", el "peligro extranjero" a la soberanía y la "amenaza al sistema democrático". ${ }^{24}$

Dentro de este contexto de alarma sobrevino el debate de hasta qué punto "la Editorial del Estado" se transformaría en un instrumento de reproducción comunista. Este órgano, llamado a publicar "nuestros intelectuales", era peligrosamente rondado, por "elementos" como Carlos Luis Fallas. El argumento se fundamentó en el acceso a puestos, "oficiales o semioficiales", desde los cuales se brindaban las "magníficas condiciones para realizar su propaganda". Y fue insistente al considerar "que un Estado que tiene colocado al comunismo fuera de ley, les facilite a dirigentes de ese mismo partido nada menos que la dirección de la única editorial nacional". ${ }^{25}$

El temor se originó por el nombramiento de la primera Asamblea de Autores. En estos años, la Asamblea funcionó como una agrupación de artistas nacionales encargada de nombrar al Consejo Directivo. Aunque Fallas estuvo en otras convocatorias, como en el grupo de escritores que apoyaron el anteproyecto de ley de la Editorial, ${ }^{26}$ su participación en esta asamblea fue mucho más cuestionada. Quizá el estatuto de organización de la Asamblea y el puesto de tesorero, ${ }^{27}$ parecían asignarle a Fallas un poder político y oficial en la toma de decisiones

24 Manuel Gamboa, "El anticomunismo en Costa Rica y su uso como herramienta política antes y después de la Guerra Civil de 1948", Anuario de Estudios Centroamericanos de Costa Rica (Costa Rica) 39 (2013). El autor se centró en el manejo táctico del discurso en las campañas electorales de 1953 y 1970, empleado para desacreditar al contrincante. Acusaciones que tuvieron especial fuerza debido a la ilegalización del Partido Vanguardia Popular y Progresista Independiente. Un discurso presente en la década de 1970 con las declaraciones del Movimiento Costa Rica Libre, las reacciones al Manifiesto Patio de Agua y la Carta Ideológica del Partido Liberación Nacional estudiados en Mercedes Muñoz, "Democracia, crisis del paradigma liberacionista y anticomunismo en la campaña electoral de 1970", Diálogos (Costa Rica) Número Especial (2008). Y existente en la década de 1980 en el marco del avance del Frente Sandinista y la potencial colaboración desde Costa Rica en la guerrilla. Para entonces, el comunista adquirió la forma de un "perturbador social", "pro terrorista", al servicio soviético, con propensión a la dictadura y a la violencia. Este "otro" ponía en riesgo la democracia nacional, la promoción de la paz y la imparcialidad costarricense en el conflicto centroamericano, tal y como se aborda en Lidieth Garro, Diario La Nación: Discurso editorial y discursos de identidad nacional 1946-1949, 1979-1982 (Maestría en Literatura Latinoamericana, Universidad de Costa Rica, 2003), 106-110.

25 s.a., "Dirigentes comunistas en la Editorial del Estado", La Nación, 2 de febrero de 1960, 6; s.a., "Penetración comunista en Editorial Nacional", La Nación, 2 de febrero de 1960, 25.

26 Asamblea Legislativa. Fernando Volio, Ley de la Editorial Costa Rica, decreto 2.366. Sección "Debate 1", 57.

27 Lía Coronado, "Asociación de Autores y Compositores Costarricenses. Editorial Costa Rica", Diario de Costa Rica, 15 de enero de 1961, 25. Esta Asamblea se conformó por: Alberto Cañas -presidente-, Juan 
de una institución del Estado. La situación anterior desencadenó una alarma en la prensa, perturbada por corroborar la noticia y visibilizar las secuelas de esta participación. Incluso, la representatividad del suceso alcanzó la década de 1990 cuando Cuevas acudió al hecho para explicar la cooptación de intelectuales comunistas al proyecto socialdemócrata. ${ }^{28}$

A pesar de la reacción en la opinión pública y el planteamiento de Cuevas, sostenemos que la Editorial tuvo una reacción comedida en sus primeros años con el "caso Fallas". Para empezar, el intelectual nunca formó parte del Consejo ni de las visitas de escritores; participación que sí tuvo, por ejemplo, Jorge Debravo, Fabián Dobles y Joaquín Gutiérrez. ${ }^{29}$ Además, ante la muerte de Calufa en 1966, el Consejo solo acordó el pago de los derechos de autor por Mi madrina y Tres cuentos; ya que "sería interesante saber cuánto le ha pagado el Partido Comunista por los derechos de la edición de Mamita Yunai"; ${ }^{30}$ novela incorporada al programa de publicaciones hasta 1987.

La receptividad de la obra de Fallas develó, desde luego, los cambios generacionales y políticos en la dirección editorial. Un Consejo que, en sus años iniciales, albergó el rechazo de Mamita Yunai por parte de Marcelino Antich, posiblemente explicado por la inspiración autobiográfica de la obra y el protagonismo del escritor en la contienda civil del 48; y que, además, experimentó el desacuerdo conservador de Lilia Ramos en emitir las condolencias de la muerte del escritor. Consejo que, posteriormente, con la dirección de Alfonso Chase declaró las obras de Fallas "patrimonio de la Editorial"31 y con la gestión de Vladimir de la Cruz, respaldó el acercamiento a los mercados socialistas interesados en autores como Calufa, Joaquín Gutiérrez, Fabián Dobles y Alfredo Cardona Peña. ${ }^{32}$

Manuel Sánchez -vicepresidente-, León Pacheco -secretario-, Carlos Luis Fallas -tesorero- y Eduardo Jenkins -fiscal-.

28 Cuevas, 98.

29 Estos escritores tuvieron cargos menores. El primero fue suplente y los otros dos secretarios. Nunca presidieron el Consejo Directivo.

30 ANCR. Acta 1, 4 de noviembre de 1966, 524. Asisten: Lilia Ramos -preside-, Ricardo Blanco, Julián Marchena, Jorge Guier, Alberto Cañas, Carlos Meléndez, Jorge Debravo, Rafael Fernández, Rafael Lucas y Marcelino Antich. Con respecto a la circulación de la tarjeta de condolencia ver Acta 1, 13 de mayo de 1966, 447. Asisten: Lilia Ramos -preside-, Lolita Zeller, Inés Trejos, Julián Marchena, Carlos Meléndez, Ricardo Blanco, Alfonso Chase y Víctor Julio Peralta.

31 Acta 24, Sesión 1.272, 7 de diciembre de 1987, 1623-1624. Asisten: Alfonso Chase -preside-, Julio Suñol, Jorge Charpentier, Arnoldo Mora, Pablo Ureña, María Salvadora y Lilly Guardia. Según el acta, la viuda de Fallas entregó las obras a Alfonso Chase. Él, para entonces presidente del Consejo Directivo, las donó a la Editorial señalando que "He pensado que sus obras deben estar en la Editorial Costa Rica porque, y también lo recuerdo con emoción, dentro de ella, en sus inicios, un grupo de jóvenes luchamos por publicarlas, junto con las de Adolfo, Fabián y Joaquín, cuando no se podía hablar de estos hombres notables". En 1976 llegó una solicitud para apoyar, sin colaboración monetaria, la conmemoración de los 10 años de fallecimiento del escritor en el Teatro Nacional, y la ECR respaldó la sugerencia. Acta 10, Sesión 663, 6 de abril de 1976, 952. Asisten: Ricardo Ulloa -preside-, Laureano Albán, Fabián Dobles, Fernando Durán, Chéster Zelaya, Federico Vargas, Albero Cañas, Francisco Zúñiga, Arturo Montero, Primo Luis Chavarría y Joaquín Garro.

32 Acta 23, Sesión 1.222 del 9 de febrero de 1987, 736. 
Al mismo tiempo, el "caso Fallas" permitió inferir las percepciones generales sobre los "otros" escritores comunistas. De alguna manera, Joaquín Gutiérrez, se enmarcó como el clásico de la literatura limonense e infantil, principalmente con Cocorí, Manglar, Puerto Limón y Murámonos, Federico. Fabián Dobles, figuró como el retratista del agro costarricense, de rostro campesino y ambiente aldeano, con Ese que llaman pueblo, El sitio de las abras e Historias de Tata Mundo. Y Jorge Debravo, era recordado como el poeta humanista, con quien la Editorial asumió un "compromiso moral"33 de publicación y llegó a aprobar la edición de cinco de sus obras en un mismo año. ${ }^{34}$

En estos términos, planteamos que la aceptación de este grupo de escritores y el reconocimiento parcializado de las obras de Fallas ${ }^{35}$ se vincularon con la lectura oficializada de sus creaciones. Las obras se leyeron según los esquemas de la literatura realista validada en la época; una estética interpretada como la expresión de la "idiosincrasia costarricense", la reproducción de imágenes nacionalistas y el "reflejo" de una realidad tradicionalmente relacionada con la angustia social. ${ }^{36}$ Según Jorge Valdeperas, incluso, el realismo poco crítico de algunos escritores de izquierda -Fallas, Dobles, Herrera y Gutiérrez- facilitó su inclusión en la literatura nacional, pues no representaron una amenaza política a los "viejos valores liberales". ${ }^{37}$ Estas obras, asimismo, por su venta asegurada, se incorporaron en las listas de prioridades para enfrentar la crisis de $1987 .{ }^{38}$

La ECR encontró tres maneras para argumentar la inclusión de estos intelectuales a sus programas de publicación. En primer lugar, los escritores se justificaron por sus "grandes méritos" en la "literatura nacional", valor previamente

33 Acta 10, Sesión 655, 10 de febrero de 1976, 938.

34 Acta 3, Sesión 334, 23 de julio de 1969, 144. Las obras se aprobaron en 1968 y fueron: Milagro abierto, Otras cosas recogidas de la tierra en dos tomos, Vórtices, Los despiertos y poemas inéditos. Esta situación desencadenó un problema con la viuda de Debravo, quien solicitó el pago de los derechos de autor y la Editorial no podía gestionar el presupuesto.

35 Para Iván Molina la comercialización de la obra de Fallas y su incorporación a la cultura oficial se explicó por la temprana muerte del escritor, una vez que su crítica social podía ser atenuada. Iván Molina, "Carlos Luis Fallas: Difusión, comercialización y estudio de sus obras. Una contribución documental”, Revista de Ciencias Sociales (Costa Rica) 133-134 (2011): 184.

36 Como ejemplos de las discusiones literarias, centradas en los caminos que debía seguir la literatura costarricense, podemos citar: Fabián Dobles, "Consideraciones sobre literatura", Brecha (Costa Rica) 2, no. 1 (setiembre de 1957): 21; Jorge Charpentier, "La novela costarricense", La Nación, 6 de setiembre de 1969, 29; Enrique Trovar, "Los buenos escritores no se producen en serie como los malos políticos", $L a$ República, 13 de junio de 1971, 9; s.a., "La novela costarricense", La Hora, 19 de noviembre de 1973, 4; Varios autores, "El escritor de hoy vive bajo la égida del editor", La Nación, 16 de diciembre de 1973, 28 C.

37 Jorge Valdeperas, 52, 64. En 1983, Manuel Picado apoyó esta perspectiva al concluir que esta generación del 40 describió la crisis social del período, pero sin crear una ruptura en las técnicas narrativas o el lenguaje. Manuel Picado, Literatura, ideología, crítica (San José, Costa Rica: ECR, 1983), 76-77. Muchos años después de estas publicaciones, Álvaro Quesada llegará a la misma conclusión de Manuel Picado. Álvaro Quesada, Breve historia de la literatura costarricense..., 87.

38 Acta 24, Sesión 1.272, 28 de setiembre de 1987, 1.428. Venta asegurada por su inclusión en las lecturas del Ministerio de Educación Pública. 
legitimado por otras instancias como los Premios Nacionales ${ }^{39}$ En segundo lugar, el Consejo remarcó que ninguna de las obras "se publicó por primera vez en la Editorial, ni ha sido reeditada por ella" ${ }^{40}$ Finalmente, el posible grado de "penetración" en la Editorial permaneció neutralizado, para tranquilidad del público, por la presencia de "anticomunistas como don Hernán Peralta y don Marco Tulio Zeledón” y de personas con "ideas tan equilibradas como Alberto Cañas y Guillermo Padilla". ${ }^{41}$

La posible filtración comunista en la Editorial del Estado condujo a la directora Lilia Ramos a elaborar un comunicado de prensa. Al interior del Consejo, Ramos insistió en desmentir la complicidad con el comunismo sugerida por el suplemento de Artes y Letras de La Prensa Libre. Y a la vez, controlar en las oficinas de venta la distribución de libros "ajenos a los intereses de la Institución"; debido a que los vendedores "son utilizados en esa labor... de carácter político. Actitud esa que puede traer un grave perjuicio al prestigio" de la Editorial. ${ }^{42}$

La aclaración anterior estuvo lejos de ahuyentar las controversias. Ante la lectura de la Liga Cívica de Mujeres, guiada por los principios de su lema "Dios y la Patria", la ECR publicaba libros con tendencia desmoralizadora y protegía al comunismo de manera tal que los escritores no daban abasto con los encargos. ${ }^{43}$ La organización implantó el imperativo de negar "a la Editorial el derecho de publicar libros "sin distingos de credos religiosos o políticos". Por su parte, el Consejo catalogó la orden como una acción discriminatoria en el campo de las ideas y una imposición de censura; señaló que esta "ingrata época de la "cacería de brujas' es cosa del pasado".

De acuerdo con lo expuesto, la Editorial y sus publicaciones fueron objeto de vigilancia. Aunque el Consejo, en su defensa, reconoció el capital literario de Carlos Luis Fallas, Fabián Dobles, Joaquín Gutiérrez y Luisa González; también se encargó de trazar los límites de su perímetro. Estas líneas de trinchera aseguraron

39 Consejo Directivo, "La Editorial frente a la nueva cacería de brujas", La Prensa Libre, 7 de octubre de 1972, 40. Con respecto al caso de $A$ ras del suelo de Luisa González, el artículo menciona: “es muy simple: publicada primero por otra empresa, nosotros la editamos después de que cosechó los aplausos de la crítica y obtuvo el 'Premio Nacional Aquileo Echeverría'".

40 Ibid. El artículo particularizó en las obras: Historias de Tata Mundo de Fabián Dobles, Mulita Mayor de Carlos Luis Sáenz, Mi madrina de Carlos Luis Fallas, Cocori de Joaquín Gutiérrez y A ras del suelo de Luisa González.

41 Guido Fernández, “Penetración comunista?”, Diario de Costa Rica, 4 de febrero de 1960, 4. Otro artículo destacó que personas como “Alberto Cañas, Juan Manuel Sánchez, León Pacheco, Eduardo Jenkins, Dinorah Bolandi, Virginia de Montealegre, Marco Tulio Zeledón y Eugenio García Carrillo, de anticomunismo largamente probado. Algunos de ellos son personas particularmente non-gratas a los comunistas", s.a. "Peligro señalado editorialmente por La Nación no existe sobre infiltración comunista en la Editorial Nacional”, $L a$ Nación, 3 de febrero de 1960, 12. Incluso uno de ellos, Marco Tulio Zeledón fue presidente del Primer Congreso Regional Anticomunista Centroamericano en 1959. Biblioteca Nacional, Memoria del Primer Congreso Regional Anticomunista Centroamericano (San José, Costa Rica: Imprenta Trejos, 1959).

42 Acta 1, 27 de mayo de 1966, 451-452, 489.

43 Liga Cívica de Mujeres Costarricenses, "Protección al comunismo", La Prensa Libre, 23 de setiembre de $1972,11$. 
la moderación de la izquierda mediante la conformación de sus miembros directivos y la selección de las obras; así como, la rendición de cuentas en la prensa para no "confundir a la opinión pública". ${ }^{44} \mathrm{La}$ argumentación recordó la publicación primigenia de estas obras en otras empresas y la distinción otorgada por otras instancias, asignándose con ello una licencia para su distribución y venta.

\section{"Esperemos a que el tiempo... nos traiga el ansiado olvido". La controversia de publicar la historia del 48}

Una segunda discusión política se desencadenó en 1968 con las tesis universitarias Historia de los Partidos Políticos: Liberación Nacional de Carlos Araya Pochet, y Costa Rica y sus hechos politicos de Óscar Aguilar Bulgarelli. En este caso, la disputa se generó por las posibles interpretaciones partidistas en la historia política de Costa Rica y, principalmente, las implicaciones en las memorias del 48. Carlos Meléndez, evaluador de las tesis, explicó que la intención fue "presentar al público lector dos versiones diferentes" de los acontecimientos, por lo que recomendaba la venta simultánea de las obras.

Las desaprobaciones provinieron de Marco Tulio Zeledón, Nelson Chacón y Claudia Cascante de Rojas. Los primeros dos objetaron la toma de partido de la obra de Pochet "por una de las fracciones políticas actualmente en plena campaña"; y en ese sentido, el empleo indebido de los "recursos del Estado en propaganda". Aunque Pochet no explicitó su trabajo como parte de una asignación partidista, se autodefinió representante de la juventud liberacionista revolucionaria. Y su obra salió a luz en un período en que el Partido Liberación Nacional (PLN) se preparaba para recuperar la administración presidencial con el triunfo electoral de José Figueres en 1970. No obstante lo anterior, las observaciones de los evaluadores giraron en torno a los contenidos tratados, sucesos históricos que, a su juicio, debían ser escritos por generaciones posteriores "no enturbiadas por la pasión o el interés partidista y militante". ${ }^{45}$

Las tesis, defendidas en historia, trasladaron a la mesa de discusión el problema de la contemporaneidad de los acontecimientos. Aunque para esta fecha habían transcurrido 20 años del enfrentamiento armado, Aguilar y Pochet advirtieron las consecuencias de estudiar la historia reciente. Se corría el riesgo, según los autores, de "herir susceptibilidades de los que aún tienen lazos afectivos", ${ }^{46}$ o bien, de filtrar una "esencia eminentemente subjetiva" ${ }^{47}$ en el tema. Siendo así, las provocaciones de las tesis eran, por un lado, la proximidad temporal; y por

44 Acta 6, Sesión 493, 3 de octubre, 429.

45 Nelson Chacón, "O estaban bien dormidos o los agarraron cabecenado", La Nación, 10 de octubre de 1968, 2.

46 Óscar Aguilar Bulgarelli, Costa Rica y sus hechos políticos de 1948: Problemática de una década (Tesis de Licenciatura en Ciencias y Letras, Universidad de Costa Rica, 1967). Tomo 1: IV

47 Carlos Araya Pochet, Historia de los partidos politicos: Liberación Nacional (Tesis de Licenciatura en Historia, Universidad de Costa Rica, 1968), 11. 
otro, el desafío de ofrecer, prácticamente por primera vez, un relato sistematizado del conflicto del 48.

Las implicaciones de sus lecturas fundamentaron la tercera desaprobación. Para Cascante de Rojas, las obras podían despertar las divisiones políticas de los "hogares costarricenses", vivida desde su experiencia, entre las estudiantes del Colegio Superior de Señoritas. En un artículo de prensa amplió su criterio, insistiendo en que:

“¿mitigarán o más bien avivarán los rencores que han venido del 48?...

No debe ser motivo de angustia para la Editorial... Esperemos a que el tiempo, buen sanador de todo, nos traiga el ansiado olvido, para que después, pero muy después, puedan ser leídas con quietud y amansamiento en el alma", ${ }^{48}$

Las obras, aprobadas con los votos negativos de Zeledón y Chacón, evidenciaron la tensión de publicar libros acerca del tema. Una resistencia asociada con las interpretaciones partidistas y las revisiones al hecho político, que de acuerdo con Fabrice Lehoucq, polarizó -como ningún otro conflicto- la política del país y la manera de entender el desarrollo de las instituciones democráticas. ${ }^{49}$ Dicha tensión se relacionó también con el concepto de investigación histórica, asumido por ambos autores como la búsqueda de "la verdad". Así las cosas, Aguilar se propuso el esclarecimiento de las "sombras" del evento, al encontrar las causas en la oposición a los gobiernos de Calderón y Picado. Sin embargo, su investigación, retadora en un entorno universitario intolerante y anticomunista, ${ }^{50}$ terminó por evaluar a los líderes involucrados en un plano narrativo de "aciertos y errores", "sentimientos sinceros", "hombres de carácter", "terquedades", “exoneración de culpas" y "patriotismo". 51

La conclusión de Aguilar cuestionó la "revolución" del conflicto y la supuesta fundación de la "segunda república". En este punto, posiblemente, Meléndez identificó la diferencia entre los autores; ya que Pochet trató de demostrar la transformación de Costa Rica con el aporte del PLN al desarrollo institucional,

48 Claudia Cascante de Rojas, "Una sesión en la Editorial Costa Rica", La Hora, 9 de noviembre de 1968, 10. En otro artículo Óscar Aguilar expresó la defensa de estas temáticas de estudio para corregir "errores históricos". Al respecto, señala que "Es necesario, derribar una serie de ídolos de barro, y darle el lugar que se merecen a muchos que hoy son olvidados y que son los verdaderos próceres de nuestra patria”, Óscar Aguilar, "Don Oscar R. Aguilar defiende su trabajo Costa Rica y sus héroes políticos de 1948", La Nación, 12 de octubre de $1968,7$.

49 Fabrice Lehoucq, Instituciones democráticas y conflictos políticos en Costa Rica (Heredia, Costa Rica: EUNA, 1998), 97.

50 Iván Molina, Revolucionar el pasado. La historiografia costarricense del siglo XIX al XXI (San José, Costa Rica: EUNED, 2012), 28. Para Molina, la importancia de la obra de Aguilar fue desafiar la versión oficial de los hechos, Los 8 años, escrita por Alberto Cañas; y reconocer las razones que llevaron a los bandos involucrados a la lucha.

51 Aguilar, 183. 
económico y educativo. Como el "triunfante" de la "revolución", según Pochet, el partido contribuyó asimismo con una maduración política en cuanto a la democracia, coherencia de tesis y representatividad de las mayorías; bases difícilmente localizables en otras propuestas políticas. ${ }^{52}$ Partiendo de esta idea, su obra parecía conciliar las fricciones al interior del PLN, que justamente para 19681969 evidenciaba divisiones ideológicas con la aparición del Manifiesto de Patio de Agua y la Carta Fundamental. ${ }^{53}$ Un partido que debía estar unido para vencer a la oposición que en las elecciones anteriores les arrebató la victoria, y que para 1970 sería su contrincante de nuevo.

De vuelta en el Consejo de la ECR, sus miembros acordaron una declaratoria de prensa para justificar las obras como un "estímulo a la cultura costarricense" y a la "libertad de expresión". Sin embargo, retomaron la reforma a Ley de 1962, en la que se especificó la prohibición de "inmiscuir a la Editorial en actividades político electorales, y asimismo intervenir, con carácter personal, en críticas y polémicas relacionadas con la labor de la Editorial". ${ }^{54}$ Siendo así, la institución ofrecía el canal para difundir estas "crónicas políticas" y explicaciones coyunturales a un tema apenas explorado, pero la citación legislativa reivindicaba el silencio de los directivos ante cualquier intento de referirse al contenido de las obras, o después de todo, de opinar sobre los hechos políticos.

\section{Publicar las corrientes de pensamiento político costarricense en la década de 1980: Un proyecto editorial malogrado}

Las polémicas anteriores se llevaron a cabo en la década de 1960 y principios del decenio de 1970. En un contexto ampliamente reconocido por las polaridades ideológicas que, para nuestros efectos, asociaron a los autores y autoras, y sus publicaciones, con pretensiones de propagación política y, por consiguiente, a la Editorial, como medio de divulgación. No obstante, el caso presentado a continuación se ubicó una década más tarde, puntualmente en los años 1980 y 1985. Tuvo su origen en la conformación de un conjunto de tomos sobre las corrientes de pensamiento político costarricense, con la edición de Joaquín Gutiérrez.

Los tomos, sin localizar hasta la fecha, pudieron vincularse con la necesidad de explicar las corrientes de pensamiento que dirigieron la administración pública o tuvieron una fuerte adhesión política en la sociedad costarricense. Más

52 Este esfuerzo explicativo se emparentó con las versiones figueristas del conflicto, las cuales acreditaron a Figueres la instauración un régimen democrático y estable. Lehoucq, 98.

53 Orlando Salazar y Jorge Salazar, Los partidos politicos en Costa Rica: 1889-2010 (San José, Costa Rica: EUNED, 2010), 133. Un conflicto ideológico que, para los autores, reflejó la oposición de un sector liberacionista, encabezado por Rodrigo Carazo, al "caudillismo" de Figueres. Los autores identifican el enfrentamiento con el Partido Unificación Nacional, posteriormente Partido Unidad Social Cristiana, como el antecedente del bipartidismo, ya que este partido estableció alianzas para constituir una oposición permanente al Partido Liberación Nacional.

54 Acta 2, Sesión 293, 11 de octubre de 1968, 336-337, 362. 
aún cuando, en esta década de crisis económica, se criticó al gobierno de Rodrigo Carazo por el encarecimiento en la calidad de vida. Y en cambio, con el ascenso de Luis Alberto Monge, se ofrecieron los programas del FMI y el AID como solución para reactivar la economía. Tomos que además buscarían explicar el comportamiento de las fracciones políticas, cuyo patrón bipartidista PLN-PUN empezaba a resquebrajarse con la aparición de una tercera fuerza en las elecciones de 1978. Para entonces, la colación de las izquierdas, escindida en 1986, manifestó interés por abrirse espacio dentro de las diputaciones..$^{55}$

El primer debate generado por los tomos ocurrió entre el editor y el encargado del "pensamiento socialdemócrata", Carlos José Gutiérrez. El editor señaló la presencia de intenciones político-partidistas en el volumen, ${ }^{56}$ interpretación reforzada por la iniciativa del autor de exhibir la obra en el Congreso Ideológico del PLN. Aunque el tomo no se publicó con el sello ECR, ni tampoco se rastrearon referencias posteriores, Gutiérrez sacó a luz su trabajo en 1986 con la Asociación Libro Libre, sello que expresó su apoyo con la publicación de esta obra a la celebración del 35 aniversario del PLN. ${ }^{57}$

Para evitar controversias de publicar una sola tendencia política, el Consejo acordó la elaboración de un segundo tomo dedicado al "pensamiento socialista-marxista". Alrededor de este último tomo y de su encargado, Vladimir de la Cruz, se produjo el segundo debate. El editor expresó sus diferencias con las selecciones realizadas de Vicente Sáenz y Manuel Mora. Con respecto a Sáenz, Gutiérrez y de la Cruz discutieron de qué manera definirlo: ¿anti-imperialista?, ¿socialista?, y según este último ¿socialdemócrata? Este conflicto de definición parecía heredarse de la polémica entre las izquierdas de la década del 30. En esta época, Sáenz como representante del Partido Socialista buscó un frente común con el Partido Comunista de Mora. Ante el malogrado intento y a pesar de las críticas al sistema político, al imperialismo estadounidense y al capitalismo agrario que lo emparentaban con la izquierda, calificó al comunismo como una "teoría exótica" y "extremista" 58 ; un personaje que, por sus controversiales cambios discursivos, para la década de 1980, aún provocaba distintas apreciaciones entre representantes de la izquierda.

Aparte de lo anterior, el editor cuestionó la selección de los discursos de Mora. A consideración de Gutiérrez, con esta antología el público "difícilmente continuará leyendo a don Manuel”. La defensa de de la Cruz fue que después del

55 Salazar, 133, 247. La unión entre las izquierdas se llamó Coalición Pueblo Unido e involucró a los partidos Vanguardia Popular, Socialista Costarricense y el Movimiento Revolucionario del Pueblo. Una fuerza adquirida en parte por la legalización del PVP en 1975.

56 Acta 14, Sesión 863, 29 de febrero de 1980, 1895.

57 Carlos José Gutiérrez, Pensamiento político costarricense: La Social democracia (San José, Costa Rica: Asociación Libro Libre, 1986). Volumen I y II.

58 Iván Molina, "Cuando las izquierdas riñen. El debate Mora-Sáenz en la Costa Rica de 1935-1936", en: Tras las huellas de Vicente Sáenz. A los 50 años de su muerte, (ed.) Gilberto Torres (San José, Costa Rica: EDUPUC, 2013) 
48, gran cantidad de costarricenses escribieron con seudónimos o en el anonimato; y la beligerancia de los escritos, firmados por Jacinto Carvajal -Mora-, condensó la capacidad organizativa desde la clandestinidad. ${ }^{59}$ A este respecto, podría pensarse que Gutiérrez reaccionaba por el contexto de la separación del Partido Vanguardia Popular y la expulsión de Mora de la Secretaría General; un personaje que, con dicha publicación, podía permanecer en una indeterminada polémica, incluso al interior de su mismo partido. La posición de la Cruz podría responder a un intento por reivindicar el espíritu de "lucha revolucionaria" de Mora, más aún cuando el dirigente comunista pronunció un llamado a la prudencia costarricense en la Revolución Sandinista y sus palabras desataron la respuesta negativa de varios sectores de la izquierda. ${ }^{60}$

El tomo ubicado de esta colección se tituló El pensamiento contemporáneo costarricense. ${ }^{61}$ A cargo de Eugenio Rodríguez Vega y Luis Demetrio Tinoco solo abordó "el pensamiento neoliberal" y el "pensamiento socialcristiano". Podría pensarse que la lejanía temporal de los pensadores, cuyos discursos surtieron efecto en la primera mitad del siglo XX, facilitó la publicación de la obra en comparación con los otros dos tomos. El comportamiento de la política electoral, y sus proyectos de sociedad en un contexto inmediato de crisis económica, guerrilla nicaragüense y declaratoria de neutralidad parecieron detener la aprobación final; una colección que volvía a dirigir la mirada sobre las principales fracciones políticas involucradas en el conflicto del 48, leídas esta vez, desde la década de 1980.

\section{La Editorial se enfrenta a la amenaza del mercado nacional de publicaciones}

En la década de 1970 surgieron una serie de editoriales y órganos de publicación focalizados en la venta de productos de investigación, material didáctico y obras literarias. Dentro de ellas se encontraron la Editorial Universitaria Centroamericana -1970-, el Departamento de Publicaciones del Ministerio de Cultura, Juventud y Deportes -1971-, el Instituto Costarricense del Libro del mismo Ministerio -1982- y las editoriales universitarias. ${ }^{62}$ La oferta de estas opciones editoriales y su interés en el mercado nacional presionaron a la ECR, más aún

59 Acta 21, Sesión 1.127, 6 de mayo de 1985, 3.992. De la Cruz argumentó su deseo por la pronta publicación "por la situación particular de don Manuel Mora, a quien lo unen afectos personales importantes"; además saldrá una biografía política, pero "no quiso presentarla aquí para que no se pensara que se aprovechaba de la situación", junto con un discurso que ha circulado en el seno de Vanguardia Popular. Acta 19, Sesión $1.061,20$ de febrero de 1984, 3.519.

60 José Merino del Río, Manuel Mora y la democracia costarricense. Viaje al interior del Partido Comunista (Heredia, Costa Rica: EFUNA, 1996), 207-214.

61 Eugenio Rodríguez Vega y Luis Demetrio Tinoco (eds.), El pensamiento contemporáneo costarricense. El pensamiento neoliberal. El pensamiento socialcristiano. Colección Biblioteca Patria (San José, Costa Rica: ECR, 1980).

62 Tales como Editorial Universidad de Costa Rica -1975-, Editorial Universidad Nacional -1976-, Editorial del Instituto Tecnológico -1978- y Editorial Universidad Estatal a Distancia -1979-. 
cuando diversos escritores y escritoras optaron por el retiro de la obra debido al retraso en la publicación.

En esta coyuntura, la capacidad de respuesta de la Editorial estuvo limitada, en cierta medida, por los condicionamientos característicos de los países latinoamericanos. Para Néstor García Canclini, la producción editorial en nuestras sociedades tiene que batallar con los bajos índices de lectura producto de sistemas educativos y servicios bibliotecarios deficientes; con los deplorables canales de distribución regional y liberarías especializadas; y con la caída del poder adquisitivo de los sectores medios o populares; todo lo cual, ligado a un restringido capital cultural, desestimulan la inversión en bienes simbólicos como los libros. ${ }^{63}$ Estos problemas estructurales sumados a la competencia por el espacio editorial, la crisis económica del país en 1980 y de la entidad en 1986-1987 provocaron una revalorización de la definición orgánica y de las prioridades institucionales de la ECR.

\section{La creación del Ministerio de Cultura reta la existencia ECR}

Desde sus años iniciales, la ECR se convirtió en un espacio de disputa. Es por ello que encontramos los intentos del Círculo de Poetas Costarricenses por incorporarse en las comisiones de lectura y obtener financiamiento para la edición de sus obras; así como las discusiones sobre la funcionalidad de la Asociación de Autores y su tentativa de escalar cargos en el Consejo. ${ }^{64}$ Visto de esta forma, los puestos de personal lector, editor o directivo en una institución cultural subvencionada por el Estado representaron la asignación de dietas. Al mismo tiempo que abría la posibilidad para la publicación de obras y la inserción de obras al canon literario oficializado por esta instancia.

Dentro de este marco de oportunidades, entenderemos la primera amenaza experimentada por la Editorial. En 1970 el futuro primer Ministro de Cultura y antiguo miembro del Consejo Directivo, Alberto Cañas, propuso una reforma de ley para absorber el organismo editorial dentro del recién creado Ministerio de Cultura, Juventud y Deportes. Al interior del Consejo, la oposición liderada por Claudia Cascante de Rojas, interpretó la legislación como una pérdida de independencia:

“Está segura la Editorial de que ella no figura dentro de esos organismos aislados y semiautónomos que, según los dictaminadores de la Ley del Ministerio de Cultura, Juventud y Deportes, son verdaderos 'gérmenes' de una acción ministerial importante y que urge 'centralizar, ampliar y fortalecer’?... ¿Está de acuerdo la Editorial Costa Rica con que se centralice o racionalice la utilización de sus recursos

63 Néstor García, La globalización imaginada (Buenos Aires, Argentina: Editorial Paidós, 2001), 153-154.

64 Acta 1, Sesión 35, 10 de mayo de 1961, 33; Acta 1, Sesión 93, 6 de noviembre de 1964, 275. 
económicos...? ¿Quedarán relegadas o anuladas las funciones de la Editorial?... ¿Es o no, una actividad política la creación de un nuevo Ministerio?". ${ }^{65}$

Cascante sostuvo su cuestionamiento al retomar las palabras del candidato a Ministro en un informe de la Asamblea General de la Asociación de Autores. En aquella sesión, Cañas insistió en la importancia de resguardar la Editorial y en "evitar que caiga en manos de quienes quieran desnaturalizar su función con fines políticos o de otro orden" ${ }^{66} \mathrm{El}$ problema de la intervención gubernamental, entendido por el mismo Cañas años atrás, era el riesgo de perder autonomía y sujetarse a las regulaciones de una nueva jerarquía institucional; condición de autonomía, declarada en su ley orgánica y retomada después para recordarle a la segunda Ministra de Cultura, Carmen Naranjo, la separación de labores entre ambas entidades. ${ }^{67}$

En 1977, Cañas presidente del Consejo en ese momento, expresó su preocupación por una segunda amenaza: el programa del Departamento de Publicaciones del MCJD. Desde su punto de vista:

"actualmente se están publicando libros que deberían editarse en la Editorial Costa Rica... anteriormente los campos editoriales de las dos entidades estaban muy bien definidos, pero últimamente se están confundiendo y el Ministerio está invadiendo el ámbito de la Editorial". ${ }^{68}$

Aunque desconocemos el catálogo de publicaciones, dicho departamento se concentró en la publicación de biografías y antologías. Para 1971, por ejemplo, apuntó la mirada en personajes como Joaquín García Monge, Carmen Lyra, Max Jiménez, Yolanda Oreamuno, Ricardo Fernández Guardia, Carlos Luis Fallas, Roberto Benes Mesén, entre otros; ${ }^{69}$ recuperados por la ECR desde sus pri-

65 Acta 4, Sesión 395, 30 de setiembre de 1970, 28.

66 Ibid.

67 La Ministra envió cartas a las "instancias adscritas" al Ministerio para circular el organigrama y evitar la celebración de actos culturales con consumo de alcohol. Acta 8, Sesión 573, 28 de mayo de 1978, 665, 694.

68 Acta 11, Sesión 698, 11 de enero de 1977, 1.085. Los directivos pactaron una reunión con el Ministro de Cultura Guido Sáenz para establecer un convenio de distribución de libros. Cuatro años atrás, Fernando Volio informó que un libro de Rufino Gil -quizá se trataba de Ciento cinco años de la vida bancaria en Costa Rica-, catalogado como libro de texto, fue reemplazado por el libro del MCJD, Historia económica y social de Costa Rica de Carlos Araya, por lo que le preocupaba "una competencia entre el Ministerio de Cultura y la Editorial... dos entidades del Estado no debían competir sino más bien completarse". Acta 7, Sesión 568, 4 de setiembre de 1973, 570.

69 Enrique Tovar, "Libros para el pueblo edita el Ministerio de Cultura", La República, 1 de noviembre de 1971. Otros autores incluidos según el artículo fueron Mauro Fernández, Pedro Pérez Zeledón, Julio Acosta, Enrique Echandi, Clorito Picado y Monseñor Thiel. Algunas listas de publicación del departamento, que siguen esta línea biográfica-histórica del artículo citado, se encuentran en Centro de Investigación y Conservación del Patrimonio Cultural, Memorias del Ministerio de Cultura, Juventud y Deportes, Departamento de Publicaciones, 1972-1973; 1974-1975; 1978-1979. Sus series, por ejemplo, para 1974-1975, se llamaron: ¿Quién fue y qué hizo?, Nos ven, Del rescate, Del folclor, Pensamiento de América, Textos 
meros años. El propósito con estas series fue la divulgación y, por consiguiente, la circulación gratuita y la venta a "precios populares". Como lo sugiere el caso descrito a continuación, posiblemente los entes directivos compitieron no por cuál institución cultural tendría la autoría del patrimonio literario, sino por cuál tendría la capacidad de captar recursos estatales y reducir los costos del producto final.

En esta línea podemos comprender la reacción frente el Instituto del Libro del MCJD, diseñado por Alfonso Chase en 1982. Para Cañas, principal analista del proyecto en el Consejo, se corría el riesgo de comprometer las utilidades asignadas por el Estado, en papelería, maquinaria, asistencia a ferias internacionales y financiamiento. ${ }^{70}$ La propuesta, concluyó el directivo, era una intervención gubernamental, para facultar al Ministerio con el poder "de fijar las normas, al Director la de dirigirlas, y a las editoriales solo las de asesorarlas". ${ }^{11}$ Bajo esta perspectiva, la acción ministerial comprometía, una vez más, la autonomía institucional, mediante la fijación de políticas editoriales, la edición de libros de texto y la participación en festivales fuera del país. ${ }^{72}$

Los conflictos con el MCJD pusieron en entre dicho los propósitos de la política cultural en el campo de las publicaciones. La "difusión artística" desde la égida liberacionista en la década de 1970 y la "promoción humana" con la tutela socialcristiana en la década de 1980, periodos en los que se desencadenaron las discrepancias, fueron interpretadas como mecanismos para centralizar las instituciones culturales. Así entendida, la amenaza del control ministerial tuvo dos dimensiones: una económica y otra simbólica. Dentro de la primera, entraba en juego la asignación de recursos y el manejo de los presupuestos -ordinarios y extraordinarios- otorgados por el Estado. Como parte de la segunda, se corría el riesgo de regimentar por primera vez las normas de la producción literaria en un solo ente rector y, asimismo, perder la representatividad y la apertura de contactos editoriales en el exterior.

breves y extraordinarios, Revistas. Con base en un levantamiento de sus obras, podemos argumentar que durante de un total de 824 obras aprobadas durante 1960-1980, la novela y la poesía obtuvieron los porcentajes más altos, $21 \%$ y $20 \%$ respectivamente; antecedidas solo por las obras especializadas - $27 \%$-.

70 Acta 16, Sesión 980, 14 de julio de 1982, 2.820. Un ejemplo de la competencia por el patrocinio fue la asistencia a la Feria Internacional del Libro en Londres del 7 al 11 de junio de 1982, en donde la Ministra Marina Volio decidió enviar como represente a Alfonso Chase, en lugar de Virginia Guell administradora de la ECR.

71 Acta 16, Sesión 980, 14 de julio de 1982, 2.827.

$72 \mathrm{Ibid}$. Un artículo que sintetiza la posición del Instituto del Libro desde la perspectiva de Alfonso Chase se encuentra en s.a., "Pretenden coordinar labor de editoriales públicas y privadas", Universidad, 25 de junio - 1 de julio de 1982, 4 . 


\section{Consecuencias de una política editorial ausente. La ECR se enfrenta a nue- vas editoriales y a la crisis económica}

La competencia por el mercado nacional se hizo presente con la aparición de nuevas alternativas editoriales para los escritores. Así, por ejemplo, en 1984 Adela Ferreto anunció a la ECR la publicación de las obras de Carlos Luis Sáenz en EUACA y en 1986 Joaquín Gutiérrez la comercialización de Cocorí con EDUCA. ${ }^{73}$ A pesar de un continuo envío de cartas para evitar la entrega de las obras, Ferreto y Gutiérrez argumentaron la tardanza en la publicación por parte de la ECR y la oportunidad de trascender la frontera nacional con las nuevas editoriales. La administración general advirtió el espacio ganado por esta competencia y "la necesidad de crear una agresiva estrategia de ventas que permita sobresalir a la Editorial -incluso mediante el obsequio de libros-". ${ }^{74}$

El hecho reflejó un conjunto de presiones que terminarían con la redefinición orgánica de la Editorial. Para empezar, la ECR solo tuvo cobertura del mercado costarricense y su proyección al área centroamericana se limitó por "los problemas políticos de la región". ${ }^{75}$ Una ventaja comparativa lograda, por ejemplo, por EDUCA, cuya red de distribución abarcó Centroamérica, Panamá, México, Suramérica, Estados Unidos y España, ${ }^{76}$ y estuvo financiada por cinco universidades centroamericanas. El potencial consumo centroamericano fue, quizá, el estímulo para que el Consejo acordara en 1985 "impulsar la edición de literatura centroamericana en la rama de la narrativa", ${ }^{77}$ iniciando con la obra del autor panameño Enrique Jaramillo Leví.

Adicionalmente, este hecho reveló la ausencia de una legislación para resguardar los derechos de autor o de propiedad literaria. Es por ello que hacia 1986

73 Acta 20, Sesión 1.093, 21 de setiembre de 1984, 3.791; Acta 21, Sesión 1.126, 29 de abril de 1985, 3.988.

74 Acta 21, Sesión 1.110 del 21 de enero de 1985, 3.888. También se decide estudiar las implicaciones legales por el hecho de que la Editorial Grijalbo tiene contratos con José León Sánchez por La isla de los hombres solos. Así como las ofertas de la Editorial Studium a los herederos de Joaquín García Monge por sus Obras completas.

75 Acta 16, Sesión 984, 11 de agosto de 1982, 2.860.

76 s.a., "23 obras publicó EDUCA en 1973”, La Hora, 15 de febrero de 1973, 2. Norma Loaiza, "Centroamérica: Región difícil para los libros”, La Nación, 1 de setiembre de 1973, 48. A pesar de esta ventaja, algunos libros dedicados a la docencia universitaria e investigación -de autores como Mario Monteforte Toledo, Edelberto Torres Rivas, Ricaurte Soler y Roberto Cerdas Cruz-, sufrieron según la entrevista de Loaiza a Ítalo López, impedimentos de circulación por ser catalogados como obras "subversivas". Hacia 1988, Carmen Naranjo señaló otro inconveniente para EDUCA. En Centroamérica los hábitos de lectura fueron desplazados por la radio y la televisión; situación que se sumó a la inexistente subvención que recibía para ese momento. Por lo que hacía un llamado para realizar pactos editoriales. Carmen Naranjo, "Problemas editorial en Centroamérica”, Káñina (Costa Rica) 12, n. 1 (1988): 165-166. EDUCA no siempre constituyó una amenaza para ECR. En 1971, el Consejo acordó una reunión con EDUCA "para tratar de romper la barrera que ponen las dos únicas firmas que editan casi todos los libros de la Editorial, a saber, Imprenta Lehman e Imprenta Trejos”. Acta 4, Sesión 413, 1 de febrero de 1971, 85. Además en 1976 se establecieron acuerdos para la publicación conjunta de los clásicos de la "literatura universal". Acta 10, Sesión 651, 13 de enero de 1976, 925.

77 Acta 21, Sesión 1.117, 4 de marzo de 1985, 3.936. 
se firmaron los primeros contratos, ubicados en actas, para garantizar la exclusividad de la ECR en la edición y exportación en el país, Centroamérica y el Caribe de obras costarricenses. Así, por ejemplo, se establecieron acuerdos legales con Joaquín Gutiérrez por Te acordarás hermano, Manglar y Chito Pinto; Ricardo Blanco por Lo que el obispo juzgare, Alfredo Cardona Peña por Viento en prosa y Vladimir de la Cruz por El 1 de mayo de 1913.

La dependencia al mercado nacional, la ausencia de una directriz editorial y el descontrol en el programa de publicaciones pusieron en evidencia que:

\begin{abstract}
"el problema de la Editorial y del país es que no existe una política editorial definida... la decisión de cuáles[obras] deben publicarse y cuáles no, es del Consejo Directivo, quien marca las pautas a seguir... esta es una Editorial muy particular puesto que hay que vender lo que presentan los autores y aprueba el Consejo, sean obras de venta rápida o lenta, contrariamente a las grandes editoriales comerciales que contrata el libro que según los estudios que realizan, es el que va a tener una favorable acogida del gran público". ${ }^{78}$
\end{abstract}

La década de 1980 fue decisiva para que los entes directivos revaluaran la rentabilidad de la institución y su alcance comercial. Es por ello que en 1982 propusieron explotar el "carácter empresarial" de la entidad, ${ }^{79}$ distanciándose con ello de la ley orgánica que postuló el valor cultural por encima del comercial. ${ }^{80}$ Asimismo, en 1985 se elaboró el primer instructivo para fijar la presentación gráfica de los libros y las normas generales de aprobación. ${ }^{81}$ Y en 1987, se estableció un proceso mucho más selectivo para la aceptación de obras; estas tendrían que contar con el juicio de personal lector externo, la Gerencia General y el Departamento de Producción. Con ello, el informe de aprobación abarcaría "el costo de producción, las posibilidades de mercado y la duración previsible del proceso total de edición". ${ }^{82}$

Estas modificaciones se insertaron dentro de un plan de reorganización institucional. Una reestructuración que formó parte de las pocas posibilidades de respuesta a la competencia editorial, al consumo del mercado nacional y al

78 Acta 16, Sesión 972, 12 de mayo de 1982, 2.756.

79 Acta 22, Sesión 1.184 del 26 de mayo de 1986, 400.

80 Asamblea Legislativa. Fernando Volio, Ley de la Editorial Costa Rica, decreto 2.366. Sección "Debate 1", "Decreto de ley" y "Proyecto".

81 Acta 21, Sesión 1.110 del 21 de enero de 1985, 3.888. Tuvo por nombre "Instructivo sobre características de los libros y normas generales sobre política editorial de la Editorial de Costa Rica". No plantearon políticas en el sentido estricto del término, solo establecieron pautas ya conocidas, tales como: "Las decisiones en torno a la publicación de textos de autores consagrados, no seguirán la vía de selección y juicio que se acostumbra, sino que se basarán en juicios de valor que emitan todos los miembros del Consejo"; "No se autorizará a Editoriales nacionales la publicación de libros de la Editorial Costa Rica, cuando los contratos de los autores estén vigentes"; "Debe someterse a votación la aceptación o rechazo de cada obra para ser publicada, aún cuando los juicios que haya recibido sean favorables o no a su edición".

82 Acta 24, Sesión 1.266, 26 de octubre de 1987. 
peligro de sobrevivencia que auguró la crisis económica de1986-1987. ${ }^{83}$ Las principales recomendaciones para rescatar la institución insistieron en el fomento de los hábitos de lectura, la creación de la figura Gerente General "como máxima posición ejecutiva de la entidad" y la asistencia de un Jefe Editor. Finalmente, para cumplir con la demanda de 1988 se planteó como prioridad de publicación los libros de texto, las lecturas complementarias y los contratos firmados. ${ }^{84}$

El estudio de quienes evaluaron concluyó ineficiencias en el asesoramiento financiero y administrativo de la Editorial, así como dificultades de recuperación económica por sí misma. La búsqueda de partidas entre diputados y diputadas, presidentes de turno o préstamos externos remarcaron la necesidad de inversión de capital. Considerando estos aspectos, la reorganización institucional mostró que su papel proteccionista ${ }^{85}$ inspirado en los cimientos de un Estado Benefactor, no era sostenible para este período, más en un país que había aprobado el recorte del gasto público y se insertaba en la lógica neoliberal con la implementación de los programas de ajuste estructural.

\section{Conclusión}

Las investigaciones sobre la Editorial concentraron su atención en el análisis empresarial y la descripción emblemática de la institución. Sus enfoques priorizaron en las propuestas de mejoramiento financiero y la labor de promoción artística en el campo de las letras. Estas perspectivas se interesaron en la

83 En 1986 se reportó un estado de alarma a partir de la falta de liquidez para pagar salarios, dietas, derechos de autoría y acreedores. En un informe presentado por Wilson García Salas, Jefe del Departamento Financiero, basado en los estados financieros de los meses de noviembre y diciembre de 1986, apuntó como principal problema el crecimiento de la producción y el decrecimiento de las ventas -así, por ejemplo, 2 de cada 3 libros editados antes de 1984 no se habían vendido-. Además, existían sobregiros en honorarios, consultorías, artículos y gastos para recepciones, viáticos y transporte. Y deudas con la Caja Costarricense del Seguro Social, el Banco Popular, el INA, Asignaciones Familiares, el Banco Nacional, la Imprenta Nacional y el Banco Central. El analista fue enfático en que esta situación se presentó desde tiempo atrás y que los estados financieros fueron aprobados por antiguos Consejos Directivos, sin tomar medidas al respecto. Acta 23, Sesión 1.221, 2 de febrero de 1987, 725-733. Ver también Acta 24, sesión 1.270 del 23 de noviembre de 1987, 1.584. Las tensiones entre miembros por el estado de gravedad, catalogado con "tendencia a la crisis", provocaron que en 1987 el Consejo Directivo se restableciera tres veces por las renuncias de sus integrantes. Esta crisis debe entenderse también en relación con las consecuencias heredadas de la crisis económica del país en 1980 que, en el caso de la producción editorial, principalmente, redujo el tiraje y aumentó el precio del libro. Consultar: Ivonne Jiménez y William Vargas, "Un año difícil para la producción editorial", Universidad, 12 de diciembre - 18 de diciembre de 1980, 20; s.a., "Inestabilidad del colón afecta producción literaria del país", Universidad, 11 de diciembre de 1981, 21. Una síntesis de la crisis de la institución se encuentra en Rocío Fernández, "El infarto de la ECR", La Nación, 21 de junio de 1987,2 C-3C.

84 Acta 24, Sesión 1.279 del 20 de noviembre de 1987, 1.580. La Comisión Asesora Especial estuvo integrada por Carlos Francisco Echeverría, Luis Alberto Chocano y Manuel Enrique Santos.

85 Acta 22, Sesión 1.203, 29 de setiembre de 1986, 548. María de los Ángeles Nassar, administradora de la ECR, presentó un informe en 1986 intitulado "Estado, autor, creación cultural y derechos autoriales". En este informe concluyó que el Estado asumía un papel proteccionista con los autores y autoras, y que, para ello, "ha puesto a su servicio un organismo que estimula y hace posible la publicación de sus creaciones". 
Frente a la encrucijada de las etiquetas políticas. Editorial Costa Rica, estado e intelectuales (1959-1987)

búsqueda de soluciones a la crisis y en la necesidad de legitimar su vigencia en el medio cultural; intenciones posiblemente explicadas por una coyuntura financiera que comprometió su existencia y competitividad. Fueron especialistas de historia y de la crítica literaria quienes, con breves aproximaciones al tema, sugirieron una función política en su creación, principalmente atribuida a la cooptación de intelectuales y al control del canon literario.

Este estudio, por su parte, profundizó en las contiendas políticas asociadas con la Editorial y demostró que la institución fue un espacio de pugna intelectual. Iniciando con su proceso de creación, se constató que la justificación de su proyecto heredó los discursos fundacionales de las instituciones culturales del siglo XIX. En este caso, se propuso potenciar internacionalmente la imagen del país y acudir a la "cultura impresa" como vehículo para divulgar las distinciones identitarias. Desde este hito fundacional se puso en evidencia el poder que tendría la publicación, al facilitar la circulación de ideas políticas en el público lector.

Los "efectos de la lectura" generaron debates entre los directivos y la prensa. Estos conflictos expresaron la polarización ideológica de la guerra fría; pero a la vez las divisiones políticas del 48 . Alrededor de este contexto, se explicó el conservadurismo de la Editorial frente al comunismo; al punto de justificar la selección de sus autores y autoras con base en el reconocimiento previo de otras instancias, tales como los premios nacionales y los programas educativos. Estos escritos se leyeron, además, con las expectativas de la época de una literatura realista-nacionalista, la cual no podía desentenderse de figuras centrales de la generación del 40, en su mayoría de izquierda.

Este combate ideológico también involucró las publicaciones sobre historia y pensamiento político. Escribir sobre la crónica del 48, los partidos políticos y sus líderes desató interpretaciones encontradas entre el personal evaluador y la intelectualidad de la opinión pública; debates que representaron, a su manera, las preocupaciones políticas en cada década de estudio. La visita a las "memorias del 48" reveló el peligro de la contemporaneidad de los acontecimientos relacionados, por lo general, con los vínculos afectivos al evento y la institución de la verdad. En estos debates también se cuestionó la intencionalidad de la obra, ya que, en medio de coyunturas electorales, se identificaron como instrumentos de propaganda política.

Los debates recuperados mostraron el capital cultural alcanzado por la Editorial. Este espacio simbólico e institucional en el medio artístico lo logró al constituirse como el principal ente de edición y difusión de la producción literaria costarricense en el período de estudio. Alrededor de estos beneficios se originaron pugnas intelectuales; juegos de poder entendidos en el marco de una instancia portadora de legitimidad literaria y retribución económica. No obstante lo anterior, estas facilidades de publicación, sin una política editorial definida la mayor parte del tiempo, terminaron por comprometer su capacidad financiera 
y competitividad frente a nuevas ofertas editoriales. Las medidas tomadas para reorganizar la institución y restablecer sus prioridades, posiblemente adelantaron las transformaciones a las que se empezó a afrontar el campo literario costarricense. Esta vez la necesidad de trascender la frontera nacional y apostar por la comercialización de los productos se impusieron como nuevas reglas de juego y reconocimiento en una sociedad en la que se abrían paso los imperativos de la lógica neoliberal. 